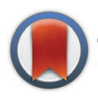

CrossMark

$\leftarrow$ click for updates

Cite this: Dalton Trans., 2015, 44 6012

Received 11th December 2014,

Accepted 16th February 2015

DOI: $10.1039 / c 4 d t 03809 f$

www.rsc.org/dalton

\title{
Fine tuning of copper(II)-chlorophyll interactions in organic media. Metalation versus oxidation of the macrocycle $\uparrow$
}

\author{
Łukasz Orzet, ${ }^{\star a}$ Bartłomiej Szmyd, ${ }^{a}$ Dorota Rutkowska-Żbik, ${ }^{\mathrm{b}}$ Leszek Fiedor, ${ }^{\mathrm{c}}$ \\ Rudi van Eldik*a,d and Grażyna Stochel ${ }^{a}$
}

\begin{abstract}
The nature of chlorophyll interactions with copper(II) ions varies considerably in organic solvents, depending on the dominant coordinative form. Besides formation of the metallo tetrapyrrolic complex, $\mathrm{Cu}(I)$ ions can cause oxidation of the pigment, reversible or irreversible, which can lead to the destruction of the macrocyclic structure. All these reaction types can be distinguished within a quite narrow range of reaction conditions. The ability to form new metallo derivatives in either metalation or transmetalation reactions is obviously limited by the concentration of the potential oxidant, but can be secured below this level via suitable composition of the reaction system. The decisive factor in the selection of a specific reaction pathway is the presence of a potential ligand that can affect the reactivity of $\mathrm{Cu}(I)$ for example by shifting its redox potential. Spectroscopic and electrochemical studies were performed in order to determine the predominant species of $\mathrm{Cu}(\mathrm{II})$ in methanol, nitromethane and acetonitrile in the presence of chloride and acetate ions, as well as to assign their appropriate oxidizing ability. This allowed us to estimate the boundary conditions for the electron transfer processes in chlorophyll-Cu(II) systems. Chlorophyll and its free base can undergo both types of electron transfer processes, however, they reveal different susceptibilities that make this class of ligands quite versatile markers in tuning the reactivity of metal ions in solutions.
\end{abstract}

\section{Introduction}

Interactions of chlorophylls (Chls; including chlorophyll $a$, $\mathrm{Chl} a$, its free base pheophytin $a$, Pheo $a$, and other derivatives) with metal ions, although not strictly related to their basic biological functions, are important for proper metabolism of the photosynthetic pigment. They are decisive not only in biosynthesis of Chla (Fig. 1) at the stage of enzyme-driven $\mathrm{Mg}^{2+}$ incorporation into protoporphyrin IX $(3,7,12,17$-tetramethyl8,13-divinyl-2,18-porphinedipropionic acid), ${ }^{1-4}$ but also in the spontaneous substitution of metal ions occurring in plants growing on soils contaminated by heavy metals. ${ }^{5}$ The latter

${ }^{a}$ Faculty of Chemistry, Jagiellonian University, Ingardena 3, 30-060 Kraków, Poland. E-mail: orzel@chemia.uj.edu.pl

${ }^{b}$ Jerzy Haber Institute of Catalysis and Surface Chemistry, Polish Academy of Sciences, Niezapominajek 8, 30-239 Kraków, Poland

${ }^{c}$ Faculty of Biochemistry, Biophysics and Biotechnology, Jagiellonian University, Gronostajowa 7, 30-387 Kraków, Poland

${ }^{d}$ Inorganic Chemistry, Department of Chemistry and Pharmacy, University of

Erlangen-Nürnberg, Egerlandstrasse 1, 91058 Erlangen, Germany.

E-mail: rudi.vaneldik@fau.de

$\dagger$ Electronic supplementary information (ESI) available. See DOI: 10.1039/ c4dt03809f

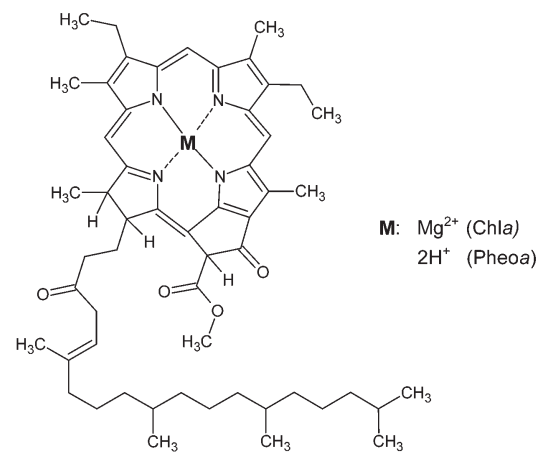

Fig. 1 Structure of Chla and Pheoa.

effect, observed clearly for $\mathrm{Cu}^{2+}, \mathrm{Zn}^{2+}, \mathrm{Cd}^{2+}$ and $\mathrm{Hg}^{2+}$, results in the irreversible loss of photosynthetic abilities. ${ }^{5-7}$ In recent years, deeper insight into the mechanisms of metal ion - Chl interactions has become important also for the development of procedures for modification and synthesis of new tetrapyrrolic complexes in terms of their potential biomedical applications. $^{8-10}$ Although the primary function of chlorophylls is related to electron transfer processes, their occurrence in biological systems is not due to pigment interactions with redox-active metal ions. Properties of natural photosystems, 
including the composition of endogenous ligands, prevent degradation of the pigment's macrocyclic structure in the presence of $\mathrm{Cu}^{2+}$ and other potential metallic oxidants.

Displacement of the chlorophyllic central ion in vivo is limited to a few metals by their abundance, water solubility and ability to adapt to the operation of the plants' ion transport system. In vitro, the site of $\mathrm{Mg}^{2+}$ can be occupied spontaneously by most divalent transition metal ions, through transmetalation or, above all, metalation conducted in acidic medium. ${ }^{11}$ The hydrophobicity of the pigment introduces significant restrictions on the reproduction of the conditions in natural photosystems. As long as the native structure of Chla is retained, the studies can be carried out only in organic solvents. Such a forced approach, belittling the possibility of referring the results directly to biological conditions, is still justified in the context of the development of strategies for the synthesis of metallotetrapyrrolic complexes in terms of their potential biomedical applications. According to our studies, organic media provide a wider variety of potential reaction courses than natural photosystems. In the presence of certain metal ions, such as $\mathrm{Cu}^{2+}$, two types of electron transfer processes can be distinguished in the formation of new metallo derivatives. ${ }^{12}$ Whereas the one-electron oxidation of the tetrapyrrolic ring appears to be reversible, thus not preventing further central ion substitution, the multi-electron process leads directly to the degradation of the macrocyclic system. ${ }^{13}$

Each of the mentioned reaction pathways is accessible for Chl-copper(II) systems within a quite narrow range of reaction conditions, as the switching between reaction pathways takes place on changing only one of three factors, namely, the oxidant concentration, solvent or counterion. The selection of the appropriate reaction pathway appears to depend on various factors, which are described in detail in this report. The analysis of the studied systems allows precise control over the reactivity of metal ions via selection of the potential ligands and adjustment of the concentration of reactants to the redox potential of the corresponding species present in solution. Precise description of the mechanisms in particular types of redox processes involving the photosynthetic pigments, will be presented in a forthcoming report.

\section{Experimental}

\section{Chlorophylls}

Chla was isolated from the cells of cyanobacterium Arthrospira maxima obtained from the Culture Collection of Autotrophic Organisms in Trebon (Czech Republic). The pigment was extracted in methanol according to Iriyama ${ }^{14}$ and purified by column chromatography on DEAE-Sepharose (Sigma, Germany), ${ }^{15}$ and then by isocratic reversed-phase high-performance liquid chromatography (HPLC) (Varian RP-C18, $250 \times 10 \mathrm{~mm}$, flow rate: $4 \mathrm{~mL} \mathrm{~min}^{-1}$ ) using methanol as the eluent. The separations were run on an HPLC system consisting of a ProStar 230 pump (Varian, USA) equipped with a TIDAS diode array detector (J\&M, Germany) for online moni- toring of absorption spectra. Pheo $a$ was obtained by a short treatment of pure Chl $a$ with glacial HAc. It was stirred for $10 \mathrm{~min}$ at $323 \mathrm{~K}$ and evaporated under argon. Dissolving the residue in acetone and evaporation were repeated until HAc was completely removed. Pheo $a$ was purified on silica gel using chloroform as eluent. Pure pigments were stored at $-20{ }^{\circ} \mathrm{C}$ under argon. All experiments were performed in dim light with freshly prepared solutions.

\section{Solvents and reagents}

All chemicals used in the experiments were of at least analytical grade. Copper(II) trifluoromethanesulfonate ( $\mathrm{CuTf}_{2}$ ), copper(II) acetate monohydrate, $\mathrm{Cu}(\mathrm{AcO})_{2}$, and tetrabutylammonium acetate, $\left(\mathrm{Bu}_{4} \mathrm{~N}\right) \mathrm{AcO}$, were purchased from Aldrich (SigmaAldrich, Germany), and tetraethylammonium chloride, $\left(\mathrm{Et}_{4} \mathrm{~N}\right) \mathrm{Cl}$, from Merck (Germany). $\mathrm{Cu}(\mathrm{II})$ chloride dehydrate and solvents, i.e., methanol $(\mathrm{MeOH})$, acetonitrile $(\mathrm{MeCN})$ and nitromethane $\left(\mathrm{MeNO}_{2}\right)$, were obtained from POCh (Poland). Electrochemical standards and electrolytes (ferrocene, tetrabuthylammonium hexafluorophosphate) were purchased from Sigma-Aldrich Co. (Germany).

\section{Spectroscopic measurements}

Lambda 35 and Lambda 950 (Perkin Elmer, USA) spectrophotometers were used for the measurement of UV-Vis absorption spectra. The temperature was fixed and stabilized during the experiments with an attached PTP-6 Peltier module. Spectroscopic titrations were carried out in $1 \mathrm{~cm}$ quartz cuvettes, whereas $0.88 \mathrm{~cm}$ quartz tandem cuvettes were used in the spectroscopic investigations of the reactions of Chla.

For the titrations small volumes (i.e., 10-25 $\mu \mathrm{l}$ ) of titrant at a concentration of $0.2-0.5 \mathrm{M}$ were added successively to $2 \mathrm{ml}$ of the titrated solution (usually $5 \mathrm{mM}$ ). The content of the cuvette was mixed by hand and the spectrum was recorded in the range covering all relevant absorption bands of the investigated compounds (from 250 to $1100 \mathrm{~nm}$ ).

The course of the reactions of Phe $a$ and Chla with $\mathrm{Cu}(\mathrm{II})$ salts was investigated spectrophotometrically within the range 350 to $1100 \mathrm{~nm}$. Solutions of the dye $(2.5 \mu \mathrm{M})$ in either $\mathrm{MeOH}$, $\mathrm{MeCN}$ or $\mathrm{MeNO}_{2}$, were mixed in the tandem cuvette with solutions of the $\mathrm{Cu}$ (II) salts of various concentration (in excess over the concentration of $\mathrm{Chl}$ to maintain pseudo-first-order conditions). The latter were prepared directly from commercially available preparations or from $\mathrm{CuTf}_{2}$ previously mixed with the salt of a suitable anion (chloride, acetate). All experiments were performed at $298 \mathrm{~K}$ under ambient pressure.

\section{Electrochemical measurements}

Cyclic voltammetry measurements were performed on an electrochemical analyzer BAS CV50W (Bioanalytical Systems, USA). A disk glassy carbon electrode was used as working electrode, and a platinum electrode and $\mathrm{Ag} / \mathrm{AgCl}$ cell as auxiliary and reference electrodes, respectively. A $0.1 \mathrm{M}$ solution of $\left(\mathrm{Bu}_{4} \mathrm{~N}\right) \mathrm{PF}_{6}$ was a basic electrolyte in suitable solvents $\left(\mathrm{MeNO}_{2}\right.$, $\mathrm{MeCN}, \mathrm{MeOH})$. Ferrocene was used to calibrate the reference electrode in non-aqueous solvents. Electrochemical titrations 
were carried out under analogous conditions to those secured in the spectroscopic titrations. Small doses of concentrated solutions of $\left(\mathrm{Bu}_{4} \mathrm{~N}\right) \mathrm{AcO}$ and $\left(\mathrm{Et}_{4} \mathrm{~N}\right) \mathrm{Cl}$ were mixed with diluted solutions of $\mathrm{CuTf}_{2}$ and the cyclic voltammograms were recorded immediately. The measurements were performed within the potential range from -1.2 to $+0.9 \mathrm{~V}$ with scan rates between 25 and $100 \mathrm{mV} \mathrm{s}^{-1}$.

\section{Theoretical calculations}

The reported theoretical results were obtained within Density Functional Theory (DFT), as implemented in Turbomole v. $6.4{ }^{16}$ with gradient-corrected Becke-Perdew functionals. ${ }^{17-21}$ Resolution of Identity (RI) approach ${ }^{22,23}$ was used for computing the electronic Coulomb interactions. The chosen methodology has already proved suitable for determination of the geometry of magnesium porphyrins, chlorophylls and bacteriochlorophylls. ${ }^{24-27}$ The basis set of def2-TZVP quality $^{28}$ was employed for all atoms. The solvation was accounted for by COSMO model ${ }^{29}$ with default radii for the elements $(\mathrm{H}=1.30, \mathrm{C}=2.00, \mathrm{~N}=1.83, \mathrm{O}=1.72)$ and $2.00 \AA$ for copper. Three $\varepsilon$ values, viz., 38.8 for acetonitrile, 32.7 for methanol, and 35.9 for nitromethane, were used in order to take into account the type of solvent used.

\section{Results and discussion}

\section{Spectroscopic tracing of the types of reactions in $\mathrm{Chl}-\mathrm{Cu}(\mathrm{II})$ systems}

The main bands in the absorption spectra of metallochlorophylls, analogously to metalloporphyrins, result from the electronic transitions between $\pi$ and $\pi^{*}$ orbitals of the macrocycle. Classic work by Gouterman, ${ }^{30,31}$ as well as more recent results from Sundholm's theoretical calculations, ${ }^{32-34}$ explain among others, the effect of metal binding on the spectral changes in the UV-Vis range. Incorporation of the metal ion into the tetrapyrrolic cavity - which is usually a spontaneous process in vitro, and in the case of certain metal ions also in vivo ${ }^{5,7}$ - proceeds under standard conditions within a timescale ranging from a few minutes (formation of Sn-Pheo $a$ in $\mathrm{MeCN}^{35}$ ) to several years (formation of Pt-Pheoa in $\mathrm{MeOH}^{25}$ ). This is accompanied by well-defined changes in the absorption spectrum, the most characteristic of which are: (i) hipsochromic shift of the $\mathrm{Q}_{\mathrm{Y}}$ band from its original position, which is located, depending on the solvent, between 660 and $670 \mathrm{~nm}$, and (ii) reduction of the number of low-intensity bands between 500 and $550 \mathrm{~nm}$. The spectra of most metallochlorophylls have been thoroughly assigned. ${ }^{11,25,36}$ Since the UV-Vis spectra of Chls reflect mainly the electronic state of the macrocycle, they are also useful in investigations of other types of interactions with the metal ion, involving electron transfer processes. This was confirmed in studies on major Chls' catabolites that provided inter alia detailed spectroscopic characteristics of the products of both one-electron oxidation processes, ${ }^{37-40}$ as well as decomposition of the macrocyclic system. ${ }^{41,42}$
The reactions of both Pheo $a$ and Chla with selected $\mathrm{Cu}$ (II) salts were performed in organic solvents, viz. $\mathrm{MeNO}_{2}, \mathrm{MeOH}$ and MeCN, thus providing non-coordinating, coordinating protic and coordinating aprotic media, respectively. Selection of $\mathrm{CuTf}_{2}, \mathrm{CuCl}_{2}$ and $\mathrm{CuAcO}_{2}$ was dictated by the need to consider the role of counter ions in the metal-tetrapyrrole interaction. Reactions were carried out at $25^{\circ} \mathrm{C}$ under pseudo-firstorder conditions with a fixed concentration of Chl $(2.5 \mu \mathrm{M})$ and a large excess of $\mathrm{Cu}^{2+}$ that varied in the range of 2.5-50 mM. Three different patterns of spectral changes could be distinguished on changing the composition of the reaction system, i.e. solvent, counter ion or metal concentration. Fig. 2 shows examples of these types of spectral changes observed in the reactions of Chla and Pheoa.

The reactions that follow pattern $\mathbf{I}$ are shown in Fig. 2A and $2 \mathrm{D}$. The most important feature of the spectral changes related to this pattern is a hipsochromic shift of the $\mathrm{Q}_{\mathrm{Y}}$ band. This change is observed for both Chla and Pheo $a$ and clearly indicates formation of a complex with the entering metal ion. Changes in the other bands are quite incomparable. Disappearance of the bands of the free base in the range 500 to $550 \mathrm{~nm}$, due to the symmetry of the compound, cannot be observed in the reactions of its $\mathrm{Mg}$ derivative. All the features observed in Fig. 2D indicate formation of a typical $\mathrm{Cu}-\mathrm{Pheo} a$ complex with a single central ion, $\mathrm{Cu}^{2+}$, placed in the cavity

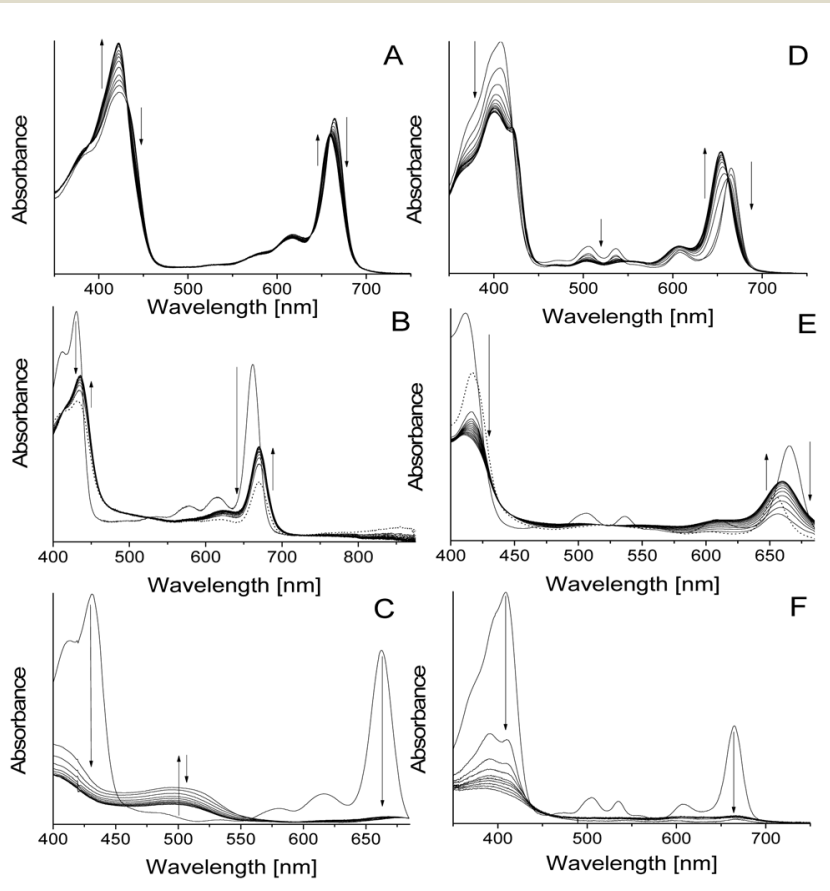

Fig. 2 Different patterns of absorption changes accompanying the reactions of Chla $(A-C)$ and Pheoa $(D-F)$ with $\mathrm{CuTf}_{2}$ in organic solvents. Pattern I observed in the reaction of Chla and Pheoa is shown in A and $D$, pattern II in B and E, and pattern III in C and F (see detailed description in the text). In the case of Chla the reactions were carried out at $\left[\mathrm{CuTf}_{2}\right]=50 \mu \mathrm{M}$ in $\mathrm{MeOH}(\mathrm{A}) ; 25 \mu \mathrm{M}$ in $\mathrm{MeCN}$ (B); and $500 \mu \mathrm{M}$ in $\mathrm{MeNO}_{2}$ (C). In the case of Pheoa, $\left[\mathrm{CuTf} f_{2}\right]=500 \mu \mathrm{M}$ in $\mathrm{MeOH}$ (D), $250 \mu \mathrm{M}$ in $\mathrm{MeNO}_{2}$ and $500 \mu \mathrm{M}$ in $\mathrm{MeCN}$. [Chla] $=$ [Pheoa] $=2.5 \mu \mathrm{M}$, $\mathrm{T}=298 \mathrm{~K}$, overall reaction time $=2 \mathrm{~h}$. 
and the plane of the macrocycle. Spectral changes depicted in Fig. 2A correspond to stabilization of the intermediate, recognized as a type of binuclear complex, $[\mathrm{Cu}-\mathrm{Pheo}-\mathrm{Mg}]^{2+}$ (compare our previous report ${ }^{12}$ ). Its breakdown and release of $\mathrm{Mg}^{2+}$ requires application of specific conditions, such as the presence of excess acetate, acting as a specific "pulling" ligand. ${ }^{43}$

Pattern II for the reactions of Chl $a$ and Pheo $a$ is represented by Fig. 2B and 2E, respectively. Regardless of the occupancy of the tetrapyrrole's cavity, the initial immediate intensity decrease in the $\mathrm{Q}_{\mathrm{Y}}$ band is followed by its slower reconstruction. Since the reconstructed band is not identical to that of the starting compound, the apparent reversibility of the process is not comprehensive and versatile. This is particularly noticeable in the case of Pheoa, where the permanent disappearance of two bands in the range 500 to $550 \mathrm{~nm}$ points to the sustainable growth of symmetry within the central cavity (see Fig. 2E). An additional band can be found in the near IR range $(>850 \mathrm{~nm})$ within the mixing stage, i.e. simultaneously with the decrease in the $\mathrm{Q}_{\mathrm{Y}}$ band. The subsequent slower disappearance of the band (a few minutes) accompanies the increase in the basic Chl absorption band. Although there is a lack of publications concerning electron transfer processes in Chl-metal systems, the changes related to the initial step of the discussed reaction type are analogous to those observed during the electrochemical oxidation of Chla. ${ }^{39,40}$ Therefore, they should be attributed to the formation of the cation radical of the pigment. Decay of this reactive species, and/or possible formation of the (new) metallo derivative, form the subject of our further studies.

The final high-lighted pattern, III, refers to the disappearance of all characteristic bands of the pigment. Despite the differences in sequences of changes observed for Chla and Pheo $a$, they undoubtedly lead to the destruction of the macrocyclic structure, in which a closed system of delocalized electrons is characterized by the distribution of energy levels giving intense and narrow $\mathrm{B}$ (Soret) and Q bands. ${ }^{32,33}$ The broad and ovoid band formed in place of the Soret band corresponds to the spectrum of 1 -formyl-19-oxobilane ${ }^{44}$ (Fig. 3), the main catabolite of chlorophyll. ${ }^{13,41,45-47}$

Such linear dihydrotetrapyrrole is formed by addition of two oxygen atoms and thus should be regarded as a product of

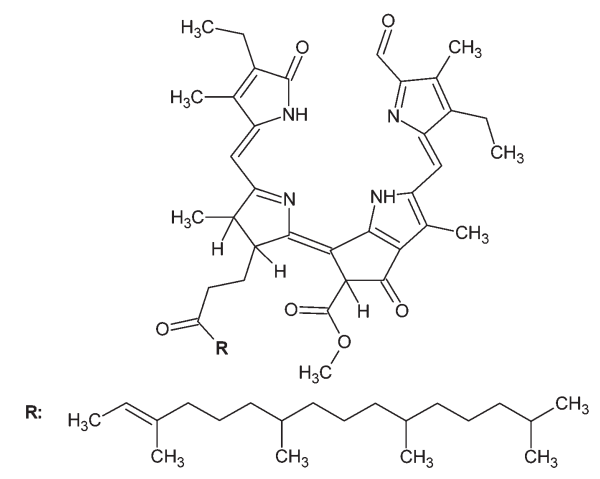

Fig. 3 Structure of 1-formyl-19-oxobilane. further (i.e. 4 electron) oxidation. Obviously, such a transformation is a completely irreversible process, which is in agreement with the spectroscopic observations. Detailed studies on the metal-catalyzed mechanism of Chl's ring-opening will be part of our future study.

In order to estimate the boundary conditions for switching between the different reaction pathways, the reactions with defined $\mathrm{Cu}(\mathrm{II})$ salts, viz. $\mathrm{CuTf}_{2}, \mathrm{CuCl}_{2}$ and $\mathrm{Cu}(\mathrm{AcO})_{2}$, were conducted within a wide range of concentrations. The upper and lower limits of the $\mathrm{Cu}$ (II) salt concentrations used in the experiments were determined by the solubility of the salt in a particular solvent (the highest [Cu(II)] used in our experiments was $50 \mathrm{mM}$ for $\mathrm{CuTf}_{2}$ in $\mathrm{MeOH}$ and $\mathrm{MeCN}$, and for $\mathrm{CuCl}_{2}$ in $\mathrm{MeOH}$ ) and a reasonable reaction progress within $24 \mathrm{~h}$. The latter restriction was due to a progressive metal-independent decomposition of the pigments in oxygenated solutions. Table 1 summarizes the ratios of $[\mathrm{Cu}(\mathrm{II})] /[\mathrm{Chl}]$ at which the reaction course changes from metalation/transmetalation (I) to reversible (II) or irreversible (III) oxidation of the macrocyclic ligand.

Table 1 clearly shows that switching between the possible reaction courses in the Chl-metal system is controlled to a considerable extent by the interactions with other components. Obviously, the ability to undergo redox processes is controlled by the electron donation and acceptance potentials, as well as the ratio of the reagents' concentrations. Therefore, it is also clear that any change in the coordination sphere must play a significant role.

To the best of our knowledge, chloride and acetate complexes of $\mathrm{Cu}(\mathrm{II})$ in organic solvents, despite the simplicity of their composition, are relatively poorly characterized. Meanwhile, speciation of $\mathrm{Cu}(\mathrm{II})$ stands for diversity of effects observed in the reactions with Chls, such as solvent-dependent acetate-induced activation of the pigment in the course of transmetalation. ${ }^{43}$

As shown by the data in Table 1, the stoichiometric presence of $\mathrm{AcO}^{-} v s$. $\mathrm{Cu}$ (II) fully protects both Pheo $a$ and Chla against oxidative degradation. The most distinct tendency to both one-electron oxidation and tetrapyrrolic ring-opening is exhibited by weakly coordinated complexes containing solvent ligands or, optionally, triflate ions. ${ }^{48}$ In turn, chloride complexes, within a broad concentration range, are involved in

Table 1 Diversity of the reaction pathways occurring at different $[\mathrm{Cu}(\mathrm{II})] /[\mathrm{Chl}]$ ratios at $298 \mathrm{~K}$

\begin{tabular}{llll}
\hline Solvent & Salt & Pheo $a$ & Chl $a$ \\
\hline $\mathrm{MeNO}_{2}$ & $\mathrm{CuTf}_{2}$ & I $(<20) ; \mathrm{II}(20-100) ; \mathrm{III}(100)$ & I $(<200) ; \mathrm{II}(>200)$ \\
& $\mathrm{CuCl}_{2}$ & I & II $(<2000) ; \mathrm{III}(>2000)$ \\
& $\mathrm{CuAcO}_{2}$ & I & I \\
$\mathrm{MeOH}$ & $\mathrm{CuTf}_{2}$ & I & I $(<50) ; \mathrm{II}(>50)$ \\
& $\mathrm{CuCl}_{2}$ & I & II \\
& $\mathrm{CuAcO}_{2}$ & I & I \\
$\mathrm{MeCN}$ & $\mathrm{CuTf}_{2}$ & I $(<20) ; \mathrm{III}(>20)$ & I $(<50) ; \mathrm{II}(>50)$ \\
& $\mathrm{CuCl}_{2}$ & I $(<20) ; \mathrm{III}(>20)$ & II $(<500) ; \mathrm{III}(>500)$ \\
& $\mathrm{CuAcO}_{2}$ & I & I
\end{tabular}


Table 2 Distribution of the reaction patterns within the range of coordinating anion's concentration, [L], at $298 \mathrm{~K},[\mathrm{Cu}] /[\mathrm{Chl}]=2000$

\begin{tabular}{|c|c|c|c|c|c|c|c|}
\hline \multirow[b]{2}{*}{ Chl } & \multirow[b]{2}{*}[\mathrm{Cu}]{$/[\mathrm{L}]$} & \multicolumn{2}{|c|}{$\mathrm{MeNO}_{2}$} & \multicolumn{2}{|c|}{$\mathrm{MeOH}$} & \multicolumn{2}{|c|}{$\mathrm{MeCN}$} \\
\hline & & $\mathrm{Cl}^{-}$ & $\mathrm{AcO}^{-}$ & $\mathrm{Cl}^{-}$ & $\mathrm{AcO}^{-}$ & $\mathrm{Cl}^{-}$ & $\mathrm{AcO}^{-}$ \\
\hline \multirow[t]{5}{*}{ Pheo $a$} & $1: 0$ & III & III & III & III & III & III \\
\hline & $1: 1$ & III & I & I & I & III & III \\
\hline & $1: 2$ & III & I & I & I & III & III \\
\hline & $1: 3$ & III & I & I & I & I/III & I \\
\hline & $1: 5$ & III & I & I & I & $\mathrm{I} / \mathrm{III}$ & I \\
\hline \multirow[t]{5}{*}{ Chla } & $1: 0$ & III & III & II & II & III & II \\
\hline & $1: 1$ & III & II & II & II & III & II \\
\hline & $1: 2$ & III & II & II & I & III & II \\
\hline & $1: 3$ & II & II & II & I & II & I \\
\hline & $1: 5$ & II & II & II & I & II & I \\
\hline
\end{tabular}

reversible electron transfer processes of Chl $a$ and simple metalation of Pheoa.

To gain more insight into the role of coordinating counter ions, the reactions of Pheo $a$ and Chla with $\mathrm{CuTf}_{2}$ in the three organic solvents were carried out in the presence of various amounts of $\left(\mathrm{Et}_{4} \mathrm{~N}\right) \mathrm{Cl}$ and $\left(\mathrm{Bu}_{4} \mathrm{~N}\right) \mathrm{AcO}$. The results of the spectroscopic observations are summarized in Table 2. Reactions were performed under pseudo-first-order conditions with a large excess of metal salt. Starting from $\mathrm{CuTf}_{2}$, which oxidizes both Chl $a$ and Pheo $a$ in each studied solvent, the electronic and macrocyclic structure of dihydrotetrapyrrole is preserved as the concentration of either $\mathrm{Cl}^{-}$or, even more, $\mathrm{AcO}^{-}$is increased.

The reactions running in the presence of a double excess of the coordinating anion are significantly slowed down with further increase in its concentration (especially chloride). One can find Pheo $a$ to be resistant to single electron donation and more prone to multi-electron decomposition, whereas Chla exhibits quite opposite tendencies. These differences can be accounted for in terms of the redox properties of Chls (see below). Moreover, the observed changes in $\mathrm{Cu}$ (II) reactivity towards Chls must be related, besides concentration, to the changes in ligand composition. More information on the $\mathrm{Cu}$ (II) speciation in chosen organic solvents was obtained from spectroscopic titrations of $\mathrm{CuTf}_{2}$, as well as from electrochemical analyses.

\section{Coordinative forms of $\mathrm{Cu}(\mathrm{II})$ in organic solvents}

The above-mentioned differences in the reaction courses and formed products, for obvious reasons, must be due to differences in the coordination forms of $\mathrm{Cu}$ (II) present in the studied systems. To shed more light on this issue, the speciation of $\mathrm{Cu}(\mathrm{II})$ was investigated in $\mathrm{MeOH}, \mathrm{MeCN}$ and $\mathrm{MeNO}_{2}$ using UV-Vis spectroscopy. The solutions of $\mathrm{CuTf}_{2}$ were titrated directly in a quartz cuvette with small amounts of concentrated $\left(\mathrm{Et}_{4} \mathrm{~N}\right) \mathrm{Cl}$ and $\left(\mathrm{Bu}_{4} \mathrm{~N}\right) \mathrm{AcO}$ solutions. The absorption spectra were recorded after each addition within the range that enabled us to track the changes in intensity and energy of the $\mathrm{d}-\mathrm{d}$ transitions. The CT transitions as being too intense except for some cases - were omitted from consideration. Fig. 4 presents an example of the changes observed in the $\mathrm{Cu}(\mathrm{II})$-anion-solvent systems.

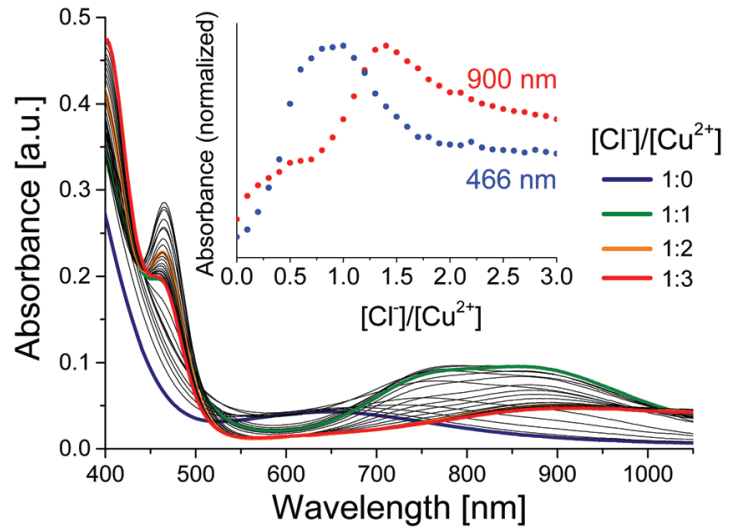

Fig. 4 Changes in the composition of $\left[\mathrm{Cu}_{m}\left(\mathrm{MeNO}_{2}\right)_{6-n} \mathrm{Cl}_{n}\right]^{2 m-n} \mathrm{com}-$ plexes. Absorbance changes that occur during the titration of $\mathrm{CuTf}_{2}$ with $\left(\mathrm{Et}_{4} \mathrm{~N}\right) \mathrm{Cl}$ in $\mathrm{MeNO}_{2}$. Inset: the titration curves recorded at 466 and $900 \mathrm{~nm}(0), T=298 \mathrm{~K}$.

On increasing the concentration of both $\mathrm{Cl}^{-}$and $\mathrm{AcO}^{-}$, the intensity of the broad band in the low energy visible and near IR ranges, increases in each solvent. Such a significant increase in the probability of $\mathrm{d}-\mathrm{d}$ transitions in the $\mathrm{Cu}(\mathrm{II})$ complex must involve a change from an almost perfect octahedral geometry to a distorted one, probably caused by the Jahn-Teller effect typical for $\mathrm{d}^{9}$ ions. This could suggest that $\mathrm{Cu}$ (II) solvate complexes reveal a reduced deformation probably due to the uniformity of the ligand field, but also due to weak metal-ligand interactions in which the $\mathrm{J}-\mathrm{T}$ effect could be less important.

A detailed description of the speciation of $\mathrm{Cu}(\mathrm{II})$-acetate complexes in $\mathrm{MeOH}$ and $\mathrm{MeCN}$ was given in our earlier reports. ${ }^{12,43}$ The results presented there, although consistent with the formation of non-reactive binuclear species bridged by up to four acetate ions, indicated a different behaviour of these complexes in both solvents driven by the excess $\mathrm{AcO}^{-}$, leading to the differentiation of their susceptibility to ligand substitution. ${ }^{43}$ Regardless of solvent, an increase in temperature causes a considerable decrease in the intensity of the band related to the $\mathrm{d}-\mathrm{d}$ transition, thus pointing to the decay of $\left[\mathrm{Cu}_{2}(\mathrm{AcO})_{4}(\mathrm{Solv})_{2}\right]$ to $\left[\mathrm{Cu}(\mathrm{AcO})_{2}(\mathrm{Solv})_{n}\right]$ species. A quite similar effect can be obtained by the application of high pressure. Spectra recorded at elevated pressure showed a $25 \%$ decrease in absorbance of $\mathrm{Cu}(\mathrm{AcO})_{2}$ in $\mathrm{MeOH}$ solution as the pressure was increased to $150 \mathrm{MPa}$ using a high pressure optical cell. ${ }^{12}$

The titration of $\mathrm{CuTf}_{2}$ with $\left(\mathrm{Bu}_{4} \mathrm{~N}\right) \mathrm{AcO}$ in $\mathrm{MeNO}_{2}$ provided information about the influence of the $\mathrm{AcO}^{-}$concentration on the change of the prevailing forms of $\mathrm{Cu}$ (II) complexes in this solvent. The band at $785 \mathrm{~nm}$, which is present in the solution of $\mathrm{CuTf}_{2}$, undergoes a considerable increase in its intensity when the $\mathrm{AcO}^{-}$concentration is increased up to 0.5 equivalents (Fig. S1 in ESI + ). At the same time, the energy of the observed transition increases, which manifests itself in a shift in the band maximum to $707 \mathrm{~nm}$. Subsequently, a ca. 30\% decrease in absorbance is accompanied by a bathochromic 
shift reaching $727 \mathrm{~nm}$ at the concentration ratio $\left[\mathrm{AcO}^{-}\right] /[\mathrm{Cu}(\mathrm{II})]$ $=2.5$. Then another increase in the absorbance is observed together with a strong hipsochromic shift (up to $636 \mathrm{~nm}$ ) at a concentration ratio of $3: 1$. Simultaneously, there is a rapid increase in the absorbance over the high-energy range of the spectrum.

Comparison of our results with Grasdalen's work on the speciation equilibria in the $\mathrm{Cu}(\mathrm{II})-\mathrm{AcO}^{-}-\mathrm{MeOH}$ system, allows to determine the formation of binuclear complexes of the type $\left[\mathrm{Cu}_{2}(\mathrm{AcO})_{4}(\mathrm{Solv})_{2}\right]$ in all the solvents tested, including $\mathrm{MeNO}_{2}$. They are distinguishable by the molar absorption coefficient, which according to Grasdalen increases from 19 through 37 to $180 \mathrm{M}^{-1} \mathrm{~cm}^{-1}$ with a change in complex composition from $\left[\mathrm{Cu}(\mathrm{AcO})(\mathrm{Solv})_{4}\right]^{+}$via $\left[\mathrm{Cu}(\mathrm{AcO})_{2}(\mathrm{Solv})_{2}\right]$ to $\left[\mathrm{Cu}_{2}(\mathrm{AcO})_{4}(\mathrm{Solv})_{2}\right]$ (cf. eqn (1)-(3)).

$$
\begin{array}{r}
{\left[\mathrm{Cu}(\mathrm{Solv})_{6}\right]^{2+}+\mathrm{AcO}^{-} \rightarrow\left[\mathrm{Cu}(\mathrm{AcO})(\mathrm{Solv})_{4}\right]^{+}+2 \mathrm{Solv}} \\
{\left[\mathrm{Cu}(\mathrm{AcO})(\mathrm{Solv})_{4}\right]^{+}+\mathrm{AcO}^{-} \rightleftarrows\left[\mathrm{Cu}(\mathrm{AcO})_{2}(\mathrm{Solv})_{2}\right]+2 \mathrm{Solv}} \\
2\left[\mathrm{Cu}(\mathrm{AcO})_{2}(\mathrm{Solv})_{2}\right] \rightleftarrows\left[\mathrm{Cu}_{2}(\mathrm{AcO})_{4}(\mathrm{Solv})_{2}\right]+2 \mathrm{Solv} \\
\left.\left[\mathrm{Cu}_{2}(\mathrm{AcO})_{4} \mathrm{Solv}\right)_{2}\right]+2 \mathrm{AcO}^{-} \rightarrow 2\left[\mathrm{Cu}(\mathrm{AcO})_{3}(\mathrm{Solv})_{0-1}\right]^{-}
\end{array}
$$

Such a clear increase in the absorbance in the low energy range in $\mathrm{MeNO}_{2}$ for $\left[\mathrm{AcO}^{-}\right] /[\mathrm{Cu}(\mathrm{II})]=1-1.5$ may be related to the formation of some type of bridged species, as shown by the subsequent decrease in the intensity of the band, which probably cannot be assigned to the incorporation of another acetate ion into the complex with a single central ion. Comparison with the results obtained in $\mathrm{MeOH}$ and $\mathrm{MeCN}$ leads to the hypothesis that the actual binuclear form is created only after exceeding the $\left[\mathrm{AcO}^{-}\right] /[\mathrm{Cu}(\mathrm{II})]$ ratio of 2.5 , which is further indicated by a significant increase in the energy of the $d-d$ transitions.

Theoretical calculations enabled the determination of the stable structures of binuclear complexes formed in each of the studied solvents with a $[\mathrm{Cu}(\mathrm{II})] /\left[\mathrm{AcO}^{-}\right]$ratio equal to 0.5 (see Fig. 5), as well as for the complexes which may be present in

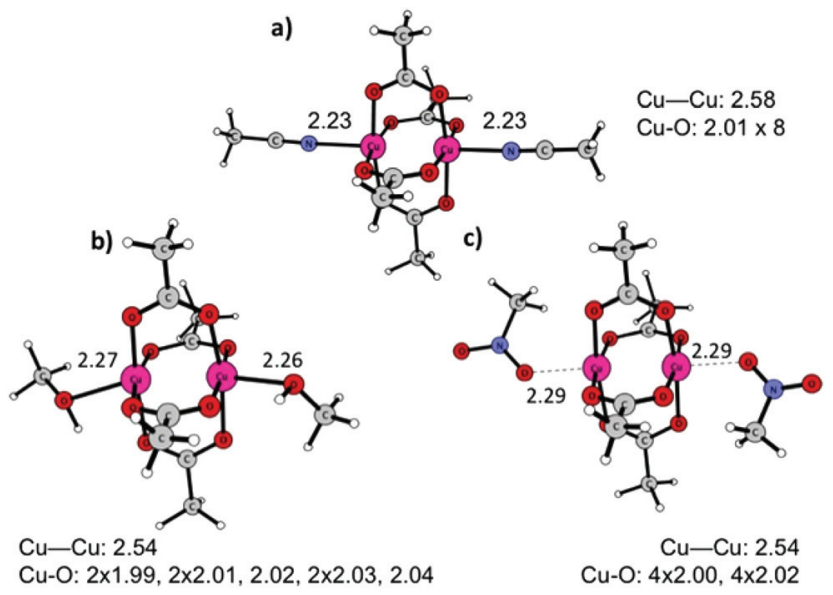

Fig. 5 Geometric structures of binuclear $\left[\mathrm{Cu}_{2}(\mathrm{AcO})_{4}(\mathrm{Solv})_{2}\right]$ species, where Solv $=\mathrm{MeCN}(\mathrm{a}), \mathrm{MeOH}(\mathrm{b})$ and $\mathrm{MeNO}_{2}$ (c).

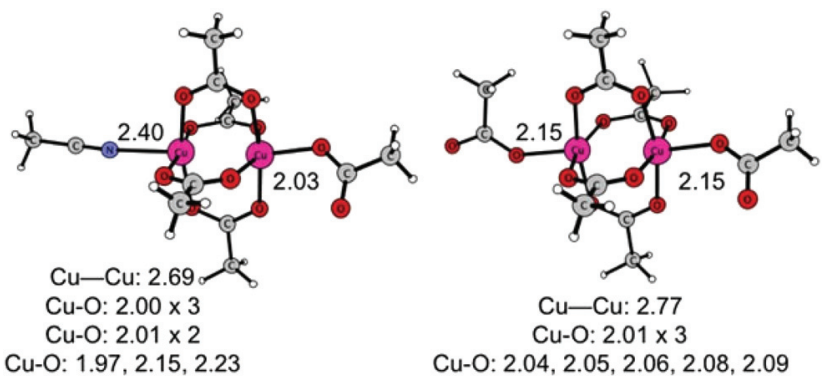

Fig. 6 Geometric structures of binuclear copper species formed in $\mathrm{MeCN}$ in an excess of acetate ions: $\left[\mathrm{Cu}_{2}(\mathrm{AcO}){ }_{5} \mathrm{MeCN}^{-}\right.$(left) and $\left[\mathrm{Cu}_{2}(\mathrm{AcO})_{6}\right]^{2-}$ (right).

an excess of acetate in $\mathrm{MeCN}$ (Fig. 6). In all the studied $\left[\mathrm{Cu}_{2}{ }^{-}\right.$ $\left.(\mathrm{AcO})_{4}(\mathrm{Solv})_{2}\right]$ systems, solvent molecules occupy axial positions at the elongation of the $\mathrm{Cu}-\mathrm{Cu}$ axis. The bond lengths between copper and solvent molecules indicate a very tight binding between $\mathrm{Cu}$ (II) and $\mathrm{MeCN}$, as indicated by the shortest bond, whereas the loosest one occurs in methanol. On the contrary, a comparison of the $\mathrm{Cu}-\mathrm{Cu}$ distances in the dimer geometries reveals that the core of the complex is the most contracted in $\mathrm{MeOH}$, whereas the least in MeCN (2.54 vs. $2.58 \AA)$. Such an arrangement may indicate that the binuclear species formed in MeCN would undergo facile scission upon binding of additional acetate ions. This hypothesis is further supported by the elongation of the $\mathrm{Cu}-\mathrm{Cu}$ distance in binuclear species caused by the substitution of MeCN molecules by $\mathrm{AcO}^{-}$ions: $2.58<2.69<2.77 \AA$ on going from $\left[\mathrm{Cu}_{2}(\mathrm{AcO})_{4}{ }^{-}\right.$ $\left.(\mathrm{MeCN})_{2}\right]$ through $\left[\mathrm{Cu}_{2}(\mathrm{AcO})_{5}(\mathrm{MeCN})\right]^{-}$to $\left[\mathrm{Cu}_{2}(\mathrm{AcO})_{6}\right]^{2-}$ (see Fig. 6).

Another substantial diversity within the tested solvents, concerns the stability of the binuclear species in the presence of an excess $\mathrm{AcO}^{-}$. In contrast to $\mathrm{MeOH}$, one can find the complexes in $\mathrm{MeNO}_{2}$ and $\mathrm{MeCN}$ to be susceptible to decomposition that is forced by the binding of additional acetate ligands (eqn (4)). A shift of the lower $\mathrm{AcO}^{-}$concentration limit in $\mathrm{MeNO}_{2}$ to the $\left[\mathrm{AcO}^{-}\right] /[\mathrm{Cu}(\mathrm{II})]$ ratio of 3 , may be somewhat surprising when the smaller donor number (DN) of this solvent (2.7) compared to $\mathrm{MeCN}$ (14.1) is taken into account. ${ }^{49-51}$ The much higher DN for $\mathrm{MeOH}$ (19.0) can in some way help to account for the higher stability of the binuclear complexes in this solvent.

Regardless of the solvent, the binuclear complexes are therefore the predominant species present in $\mathrm{Cu}(\mathrm{AcO})_{2}$ solutions. The contribution of this form, increases further with increasing concentration of $\mathrm{Cu}(\mathrm{AcO})_{2}$ (compare Fig. S1 $\dagger$ and 4 in ref. 43), which admittedly does not alter the course of the reaction with Chls but may significantly affect the results of the kinetic analysis. ${ }^{12}$

Analogously, the speciation of $\mathrm{CuCl}_{2}$ was investigated in $\mathrm{MeOH}, \mathrm{MeCN}$ and $\mathrm{MeNO}_{2}$ using UV-Vis spectroscopy. The solutions of $\mathrm{CuTf}_{2}$ were treated with small volumes of concentrated $\left(\mathrm{Et}_{4} \mathrm{~N}\right) \mathrm{Cl}$. As a consequence of increasing $\left[\mathrm{Cl}^{-}\right]$, changes were observed in two regions of the spectrum. The expected increase in absorbance in the red and near-infrared region was 
observed in each solvent, however, the maximum absorbance is far from that reached by the acetate complexes under similar conditions. On comparing the solvents, chloride and acetate complexes of $\mathrm{Cu}$ (II) achieve the molar absorption coefficients of 3.2 and $55\left(\mathrm{MeNO}_{2}\right), 5.5$ and $70(\mathrm{MeOH})$, as well as 6 and $450 \mathrm{M}^{-1} \mathrm{~cm}^{-1}$ (MeCN), respectively. Further increase in the concentration did not entail any significant changes in the absorption spectra and therefore such $\varepsilon$ values, especially for $\left(\mathrm{Et}_{4} \mathrm{~N}\right) \mathrm{Cl}$ titrated solutions, should be assigned to Cl-saturated compounds (presumably $\left[\mathrm{CuCl}_{2} \mathrm{Solv}_{2}\right]$ ), whereas in fully solvated species it does not exceed $1 \mathrm{M}^{-1} \mathrm{~cm}^{-1}$. More pronounced changes are observed in the UV-Vis region up to $500 \mathrm{~nm}$, since changes in the local environment of $\mathrm{Cu}(\mathrm{II})$ should be stronger reflected in CT than $\mathrm{d}-\mathrm{d}$ transitions.

Whereas in $\mathrm{MeOH}$ and $\mathrm{MeNO}_{2}$ a gradual increase in the absorbance is observed as the concentration of $\mathrm{Cl}^{-}$is increased, changes in the high-energy region of the spectrum in MeCN are significantly more complex (Fig. 7). This complexity is probably a consequence of the properties of the solvent itself since it also appears in the case of the acetate complexes.

In contrast to other solvents, changes in the CT transitions concern a single band: quite weak in $\mathrm{MeNO}_{2}$ where the maximum $\varepsilon$ at $469 \mathrm{~nm}$ reaches $75 \mathrm{M}^{-1} \mathrm{~cm}^{-1}$, and much stronger in $\mathrm{MeOH}$, well beyond the measurement possibilities. The difference between $\varepsilon$ values for CT and d-d transitions makes it impossible to analyze changes in the respective bands at the same level of $\mathrm{Cu}(\mathrm{II})$ concentration. For this reason we have omitted the analysis of changes in the CT band, taking also into account the fact that a decrease in $\mathrm{Cu}$ (II) concentration will entail a change in $\left[\mathrm{Cl}^{-}\right] /[$Solv $]$and thus affect the speciation. The simplest case, viz. $\mathrm{MeNO}_{2}$, shows an identical course of changes in both the absorption bands in the UV-Vis-NIR range. A plateau is reached at a ratio of 2 .

Regardless of the inability to track changes in the UV range, it can be expected with high probability that a similar situation occurs in $\mathrm{MeOH}$, and the only difference is the intensity and

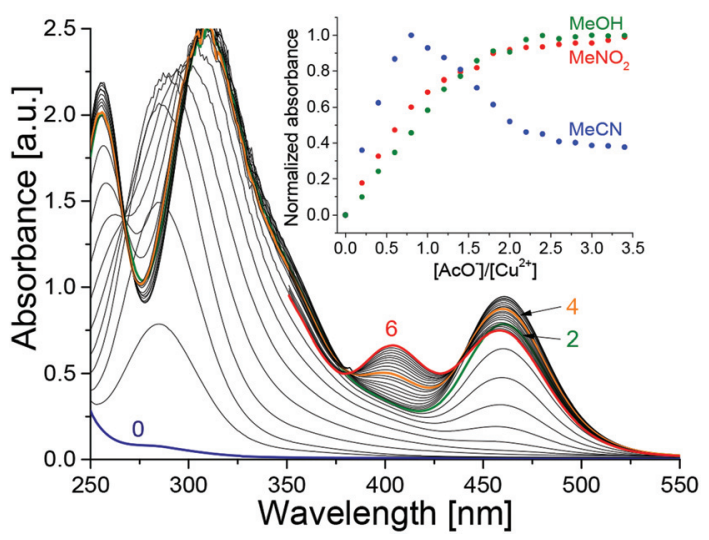

Fig. 7 Absorbance changes that accompany the increase in $\left[\mathrm{Cl}^{-}\right]$in the solutions of $0.01 \mathrm{M} \mathrm{CuTf}_{2}$ in $\mathrm{MeCN}$ at $298 \mathrm{~K}$. Inset: titration curves in the NIR range were monitored at $806(\mathrm{MeCN}), 900\left(\mathrm{MeNO}_{2}\right)$ and $890 \mathrm{~nm}$ $(\mathrm{MeOH})$. Coloured numbers on the graph indicate spectra recorded for specific $\left[\mathrm{AcO}^{-}\right] /\left[\mathrm{Cu}^{2+}\right]$ ratios. energy of the CT bands. A better insight can be obtained with respect to the structural analysis of chloride complexes in aqueous solution. X-ray studies reported by D'Angelo et al. led to the determination of the order of filling in the spatial position of the octahedral $\mathrm{Cu}$ (II) aqua complex by entering chloride ions. ${ }^{52}$ According to this work, the experimental coordination number (CN) for $\mathrm{Cl}^{-}$in aqueous solutions of $\mathrm{CuCl}_{2}$ is only 0.4 . Introduction of the second charged ligand requires application of a considerable excess and the average $\mathrm{CN}=2$ is achieved at the concentration ratio of $1: 30$. While the first $\mathrm{Cl}^{-}$ligand is introduced in the equatorial position as indicated by the analysis of bond lengths, the second one substitutes a water molecule in the axial position.

In the case of organic solvents of weaker coordination ability, it is expected to shift the formation of electrically neutral complex species to lower values of $[\mathrm{Cu}(\mathrm{II})] /[\mathrm{L}]$. Such predictions are supported by the decreasing polarity of the neutral ligands, and with it the dielectric constant, whereby the solvent molecules must make a smaller contribution to the increasing enthalpy of binding of the anionic ligands due to the stronger shielding effect of the central ion and electrostatic repulsion between the polarized molecules. This may provide some explanation for saturation of the absorbance of $\mathrm{Cu}$ (II) complexes that is observed with increasing $\left[\mathrm{Cl}^{-}\right]$exceeding a double excess relative to the [Cu(II)]. Moreover, less polar solvents stabilize the charged particles to a lesser extent, which further facilitates the inclusion of the second chloride ion into the coordination sphere.

Seeking a clarification for the relative complexity observed in MeCN, particularly related to the chloride complexes, but also discernible in the case of acetate complexes, could be due to the cleavage of electronic levels in systems revealing the J-T effect. Since MeCN ligands are exceptionally weakly coordinated to $\mathrm{Cu}(\mathrm{II})$, as suggested by the results of DFT calculations, the octahedral distortion involving elongation of the axial bonds is especially pronounced (compare data in Table 3). Such large J-T effects should result in stronger abolition of the degeneration of $e_{g}$ and $t_{2 g}$ orbitals, thus allowing the appearance of an additional $\mathrm{d}-\mathrm{d}$ transition. In contrast, the geometry of mixed $\mathrm{H}_{2} \mathrm{O}$ /solvent complexes in $\mathrm{MeOH}$ and particularly in $\mathrm{MeNO}_{2}$, are nearly octahedral (Table 3) and lead to the simplification of the absorption spectrum.

Given that the structures of $\mathrm{Cl} / \mathrm{MeCN}$ complexes of $\mathrm{Cu}$ (II) have not been fully characterized, the possibility of greater isomeric diversity in this solvent should also be considered. The rigor of a cis isomerism in aqueous solution is certainly weakened when changing the solvent. Such an approach in turn applied to acetates, would provide an additional argument for different effects of the excess $\mathrm{AcO}^{-}$on the stability of binuclear structures. The chloride ions, although known for their clustering properties and the specific efficiency in inner sphere electron transfer processes, do not form exceptional thermodynamically stable bridged complexes with $\mathrm{Cu}(\mathrm{II})$. Although there is evidence for the existence of such combinations in the solid phase, there is lack of both literature and experimental proof on the subject in solution, suggesting the 
Table 3 Geometric parameters of different $\left[\mathrm{CuCl}(\mathrm{Solv})_{5}\right]^{+}$and $\left[\mathrm{CuCl}_{2}(\mathrm{Solv})_{4}\right]$ species obtained from DFT calculations

\begin{tabular}{|c|c|c|c|c|}
\hline Complex & $\mathrm{CN}\left(\mathrm{Cu}^{2+}\right)$ & No. $S^{a}$ & $\mathrm{R}_{\mathrm{Cu}-\mathrm{Solv}}[\AA]$ & $\mathrm{R}_{\mathrm{Cu}-\mathrm{Cl}-}[\mathrm{A}]$ \\
\hline$\left[\mathrm{CuCl}(\mathrm{MeCN})_{5}\right]^{+}$ & 5 & 1 & $1.989 ; 1.989 ; 2.051 ; 2.217$ & 2.282 \\
\hline$\left[\mathrm{CuCl}(\mathrm{MeOH})_{5}\right]^{+}$ & $3^{b}$ & 3 & $1.960 ; 1.961$ & 2.559 \\
\hline cis- $\left[\mathrm{CuCl}_{2}(\mathrm{MeCN})_{4}\right]$ & 4 (Distorted tetrahedron) & 2 & $2.013 ; 2.017$ & $2.221 ; 2.225$ \\
\hline trans $-\left[\mathrm{CuCl}_{2}(\mathrm{MeCN})_{4}\right]$ & 4 (Distorted square) & 2 & $1.956 ; 1.956$ & $2.258 ; 2.258$ \\
\hline cis $-\left[\mathrm{CuCl}_{2}(\mathrm{MeOH})_{4}\right]$ & 4 (Distorted square) & 2 & $2.029 ; 2.137$ & $2.185 ; 2.252$ \\
\hline trans $-\left[\mathrm{CuCl}_{2}(\mathrm{MeOH})_{4}\right]$ & 4 (Distorted square) & 2 & $2.035 ; 2.036$ & $2.253 ; 2.253$ \\
\hline
\end{tabular}

${ }^{a}$ Number of solvent molecules in the $2^{\text {nd }}$ coordination sphere. ${ }^{b} \mathrm{MeOH}$ prefer to make hydrogen bonds between one and the other rather than to coordinate $\mathrm{Cu}(\mathrm{II})$ ion. ${ }^{c} 5^{\text {th }}$ ligand is placed in the sixth coordination position, but the Cu-Solv distance is $2.829 \AA$.

monomeric complexes as predominant species in such solutions. Small changes in the $\varepsilon$ values upon dilution (Fig. S2 in ESI $\dagger$ ) and increasing temperature (Fig. S3 in ESI $\dagger$ ), rather indicate dissociation of $\mathrm{Cl}^{-}$from the neutral $\mathrm{Cu}$ (II) complexes than cleavage of the $-\mathrm{Cl}$ - bridges. Reports of the coexistence of cationic and anionic forms, namely $\left[\mathrm{CuCl}(\mathrm{Solv})_{n-1}\right]^{+}$and $\left[\mathrm{CuCl}_{3}-\right.$ $\left.(\mathrm{Solv})_{n-3}\right]^{-}$, in certain organic solvents such as DMF, could not be sufficiently confirmed in the present study.

Based on the theoretical calculations for $\left[\mathrm{CuCl}_{2}(\mathrm{Solv})_{2}\right]$ complexes, we attempted to rationalize the observed differences in UV-Vis spectra observed in the studied solvents. The geometric structures of the selected coordinative forms of $\mathrm{Cu}(\mathrm{II})$ with chloride ions in the studied solvents are proposed on the basis of theoretical modelling (see Table 3 and Fig. S4 in ESI†). It appears that the coordination number of copper is reduced upon ligation by the anionic ligand.

The results of our theoretical modelling show that the immediate surroundings of the $\mathrm{Cu}$ (II) ion may vary in MeCN between distorted tetrahedron and distorted square for cisand trans-systems, respectively (see Table 3). Such a change may give rise to the complication of the UV-Vis spectra, not observed for the analogous systems in $\mathrm{MeOH}$ and $\mathrm{MeNO}_{2}$, where for both cis- and trans-complexes the immediate surroundings of the central metal is the same (distorted square for $\mathrm{MeOH}$ and square for $\mathrm{MeNO}_{2}$ ). This explanation may seem unsatisfactory when comparing the Gibbs free energy difference between the cis- and trans-isomers in $\mathrm{MeCN}$, which equals $-27.4 \mathrm{~kJ} \mathrm{~mol}^{-1}$, more than that found for $\mathrm{MeOH}$ $\left(-21.2 \mathrm{~kJ} \mathrm{~mol}^{-1}\right)$ and $\mathrm{MeNO}_{2}\left(2.0 \mathrm{~kJ} \mathrm{~mol}^{-1}\right)$. However, knowing that MeCN is a labile ligand, it may be assumed that rapid isomerisation of the complex, results in the co-existence of the cis- and trans-isomers in solution and, consequently, copper ions in different geometrical environments. Such an isomerisation may occur also in other solvents, nevertheless, not changing the geometry surrounding the metal ion.

\section{Boundary conditions for electron transfer processes}

As shown above, the redox processes in transition metal ion (metallo)dihydrotetrapyrrole systems are affected by the choice of solvent, and most of all the coordinating counter ion. Both, acetate that prevents oxidation of the macrocycle, as well as chloride that favours reversible one-electron processes, fulfil their functions in this system not only through impact on the reduction potential of $\mathrm{Cu}(\mathrm{II})$, but also through their individual characteristics. However, it is the redox potential of the reactive species present in the solution that determines the limiting concentrations required to switch the reaction pathways.

In order to determine the redox potentials of the main coordination forms of $\mathrm{Cu}(\mathrm{II})$ constituting the studied systems, electrochemical titrations were performed on $\mathrm{CuTf}_{2}$ in each solvent using the approach applied in the spectroscopic determination of the speciation. Small amounts of concentrated $\left(\mathrm{Et}_{4} \mathrm{~N}\right) \mathrm{Cl}$ and $\left(\mathrm{Bu}_{4} \mathrm{~N}\right) \mathrm{AcO}$ were added to the titrated solutions of $\mathrm{Cu}$ (II) solvate complexes and the CVs were recorded. The same technique was also applied to determine the redox potentials of the pairs consisting of the tetrapyrrolic compounds, namely Pheo $a$, Chl $a$ and $\mathrm{Cu}-\mathrm{Pheo} a$, and their respective cation radicals. Sample voltammograms recorded in $\mathrm{MeCN}$ are shown in Fig. 8.

Comparison of the voltammograms for Chls and various $\mathrm{Cu}(\mathrm{II})$ species indicates the possibility of the occurrence of electron transfer between the incoming metal and the tetrapyrrolic ligand. Detailed analysis of the results of the electrochemical measurements (see Table 4) provides a basis for predicting changes in the pathways of the Chls reactions with $\mathrm{Cu}$ (II). The comparison of the redox potentials of both photosynthetic pigments and various coordination forms of $\mathrm{Cu}$ (II) appearing in organic solvents in the presence of potential anionic ligands, allows to determine the limits for reactant concentrations at which a ligand substitution type of reaction is expected to change into an electron transfer process.

The redox behaviour of photosynthetic pigments have been extensively studied and described for a variety of simple and complex systems. ${ }^{38-40,53-55}$ The basic context of this type of research was usually the primary photosynthetic electron transfer. The results provided a detailed characterization of both cationic ${ }^{39,55}$ and anionic ${ }^{54,55}$ radicals of Chls, the products of one-electron transfer that are strictly related to the biological systems. Moreover, these studies have established a linear relationship between the redox potential of the $\pi$-electron system and the electronegativity of the central metal ion. ${ }^{36}$ Such dependence is also known for metalloporphyrins, thus indicating the generality of this effect in relation to tetrapyrrole-derived compounds. ${ }^{56}$ 


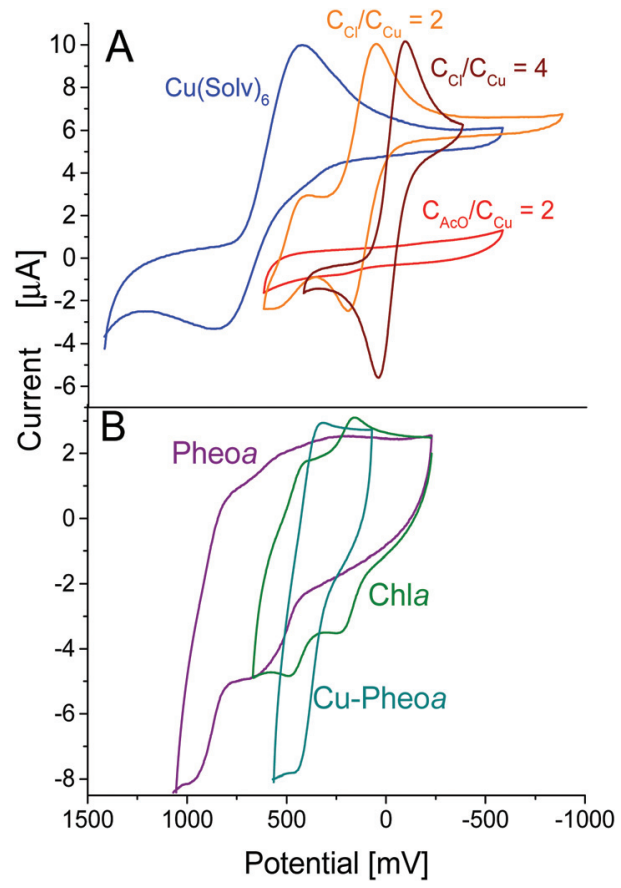

Fig. 8 A comparison of the cyclic voltammograms of $\mathrm{Cu}^{2+}$ species (A) with Chls (B) in $\mathrm{MeCN}$ - the original plots recorded versus $\mathrm{Ag} / \mathrm{AgCl}$ electrode.

Table 4 Observed half-wave potentials of Chls and $\mathrm{Cu}(॥)$ complexes, related to $\mathrm{NHE}$ by comparison with the $\mathrm{FC}^{+} \mid \mathrm{FC}$ couple

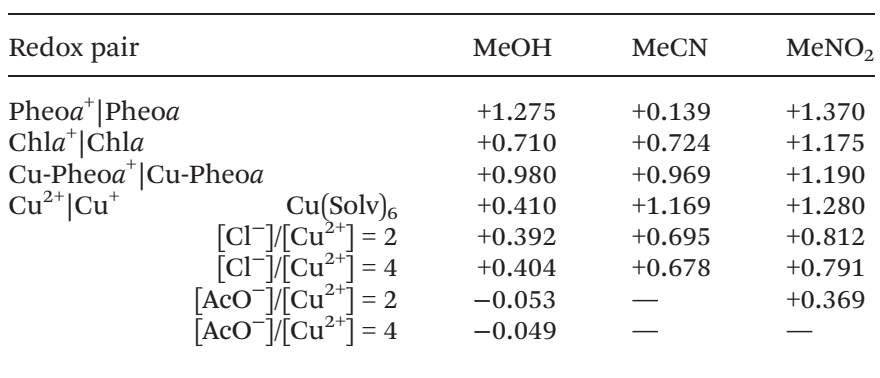

Our results are in good agreement with the above observations. First of all, the Fuhrhop's electropotential series ${ }^{56}$ is maintained in each of the tested solvents (Fig. 8B, Table 4). The difference between the half-wave potential of Chla and its free base varies between different solvents, which to some extent may be elucidated by solvation and other solvent-dependent intramolecular interactions. Location of $\mathrm{Cu}-\mathrm{Pheo} a$ in the middle of the scale provides a simple explanation for the loss of photosynthetic properties of plants growing on soils contaminated by this metal. ${ }^{7}$

Differences in the solvation of the individual pigments are also reflected in the shapes of the oxidation and reduction bands. Regardless of the subtle changes at the transition between the solvents, it should be noted that the shape of the voltammogram of Pheo $a$ indicates practically irreversibility of the one-electron oxidation. This pattern is essentially preserved in all tested solvents, thus remaining in conformity with the conclusions drawn from the observations of the reactions with $\mathrm{Cu}$ (II). In the case of $\mathrm{Chl} a$, both oxidation and reduction signals point to full reversibility of the electron transfer process. It is somewhat weaker in MeCN (Fig. 8B) and also reflected in the course of the reactions with $\mathrm{Cu}$ (II) for low $[\mathrm{L}] /[\mathrm{Cu}]$ values.

This and not another redox characteristic of photosynthetic pigments, probably stands in a logical relationship to the structure and activity of the " $\mathrm{Z}$ scheme" in the light-dependent phase of photosynthesis. Assuming that excited Chla, while maintaining an appropriate scale, retains the ability for reversible oxidation, its photo-induced ionization meets all the criteria required for the initiator of the electron transfer chain, starting from the oxygen evolving complex. Meanwhile Pheoa, being the first acceptor in PSII, must actually provide only the reversibility of the reduction process. It can, therefore, be concluded that while maintaining the same range of radiation absorbed, the choice of the $\mathrm{Mg}$ complex as the key element of the antenna system is dictated by both twice the efficiency of the solar energy conversion, expressed by $\varepsilon$, and the expected difficulties in returning to the ground electronic configuration of the Pheo $a^{+}$form.

The change in solvent and, in particular, the use of a salt with a coordinating anion, have as expected a huge effect on the oxidative properties of $\mathrm{Cu}$ (II) (compare Fig. 8A). This effect is clearly pronounced in the case of acetate complexes. Increasing the ratio of $\left[\mathrm{AcO}^{-}\right] /[\mathrm{Cu}(\mathrm{II})]$ from 0 to 2 entails reduction of the half-wave potential of the $\mathrm{Cu}$ (II) center by more than $0.45 \mathrm{~V}$ in $\mathrm{MeOH}$ and twice as much in $\mathrm{MeNO}_{2}$.

While increasing the concentration of the coordinating anion, the shape of the voltammograms recorded in $\mathrm{MeOH}$ indicates the presence of at least two coordinative forms of $\mathrm{Cu}(\mathrm{II})$, as well as adoption of partially irreversible characteristics. On turning to an excess $\mathrm{AcO}^{-}$, the signal is simplified which is understandable given the fact that under these conditions almost exclusively two-centre forms are present in solution. The difference between the anode and cathode potential may indicate the partial irreversibility of the redox couple, or results from the coupling of two metal centres.

The increase in $\mathrm{AcO}^{-}$concentration in $\mathrm{MeNO}_{2}$ is accompanied by flattening of the recorded signal, which practically disappears in MeCN (Fig. S5 in ESI $\dagger$ ). Lack of evidence for electron donation or acceptance by the $\mathrm{Cu}$ (II) center observed over a wide range of potential, whatever it is caused by, indicates the disappearance of the danger of pigment oxidation in the presence of these ions and preservation of the non-redox pathways of both metalation and transmetalation of Chls.

The reduction of the half-wave potential of the $\mathrm{Cu}^{2+} \mid \mathrm{Cu}^{+}$ couple occurs also in the presence of chloride ions (Table 4). This effect is smaller, particularly for a ratio of $\left[\mathrm{Cl}^{-}\right] /[\mathrm{Cu}(\mathrm{II})]=2$, i.e. for the coordination forms present in solutions of $\mathrm{CuCl}_{2}$. One can observe the anodic peak to disappear and the amount of signalling components to be reduced with increasing concentration of $\mathrm{Cl}^{-}$. This finding is in agreement with studies on $\mathrm{Cu}(\mathrm{II})$ speciation. Whereas this effect is very pronounced in 
MeCN and $\mathrm{MeNO}_{2}$, it is barely noticeable in $\mathrm{MeOH}$ (compare Table 4).

In order to estimate the boundary conditions for electron transfer processes between Chls and $\mathrm{Cu}$ (II) complexes, the basic Nernst eqn (5) was used under standard temperature and pressure conditions (298 K and 1 bar, respectively).

$$
\Delta G^{\circ}=-F\left(E_{\mathrm{Cu}}-E_{\mathrm{Chl} a}+\frac{R T}{n F} \ln \frac{[\mathrm{Cu}]}{[\mathrm{Chl} a]}\right)
$$

Hence, for a one-electron transfer processes:

$$
\frac{[\mathrm{Cu}]}{[\mathrm{Chl} a]}=\exp \left(\frac{F}{R T}\left(E_{\mathrm{Cu}}-E_{\mathrm{Chl} a}\right)\right)
$$

The concentration ratios calculated for $\Delta G=0$, listed in Table 5, should be regarded as the apparent values, working on the assumption that $100 \%$ of $\mathrm{Cu}(\mathrm{II})$ is present in its reactive form. This assumption is quite consistent with reality, but wrong for $\mathrm{CuAcO}_{2}$ solutions in which, within the tested range of concentration, non-reactive binuclear complexes are the predominant species. At higher $\mathrm{Cu}$ (II) concentration, and thus larger $[\mathrm{Cu}(\mathrm{II})] /[\mathrm{Chl}]$, clustering is maintained and, therefore, the values given in Table 5 are underestimated.

Theoretically estimated concentration ranges of $\mathrm{Cu}(\mathrm{II})$, which favour oxidation of the dihydrotetrapyrrolic ring, are in general agreement with the experimental observations of the reaction courses. Under pseudo-first-order conditions, a relatively small excess of metal must induce the removal of an electron from the $\pi$-electronic system of the macrocycle. According to the results of the electrochemical measurements, the reaction of Pheo $a$ in $\mathrm{MeOH}$ should be the exception. However, this was not confirmed in a direct experiment. A particularly low activation threshold for the redox process in MeCN appears to be due to poor coordination of $\mathrm{Cu}$ (II) by solvent molecules, as concluded from DFT calculations.

The lower oxidation potential of Chla obviously makes it more sensitive towards a metal ion. Oxidation is observed in a wide range of concentrations of the chloride complex, while the $\mathrm{AcO}^{-}$ions virtually secure selection of the non-redox pathway. In the case of Pheoa, even coordination of $\mathrm{Cl}^{-}$ induces an analogous effect, with the exception of $\mathrm{MeNO}_{2}$

Table 5 Minimum theoretical excess of [Cu(II)] on pigment necessary for electron transfer process. Data calculated on the basis of the redox potentials determined for Chla and Pheoa as well as for CuTf 2 in the presence of different concentrations of $\left(\mathrm{Et}_{4} \mathrm{~N}\right) \mathrm{Cl}$ or $\left(\mathrm{Bu}_{4} \mathrm{~N}\right) \mathrm{AcO}$

\begin{tabular}{lllll}
\hline Chl & $\mathrm{Cu} / \mathrm{L}$ & $\mathrm{MeNO}_{2}$ & $\mathrm{MeCN}$ & $\mathrm{MeOH}$ \\
\hline Chl $a$ & $\mathrm{CuTf}_{2}$ & $1.67 \times 10^{-2}$ & $2.97 \times 10^{-8}$ & $1.19 \times 10^{5}$ \\
& {$\left[\mathrm{Cl}^{-}\right] /\left[\mathrm{Cu}^{2+}\right]=2$} & $1.38 \times 10^{6}$ & $3.09 \times 10^{0}$ & $2.39 \times 10^{5}$ \\
& {$\left[\mathrm{Cl}^{-}\right] /\left[\mathrm{Cu}^{2+}\right]=4$} & $3.13 \times 10^{6}$ & $6.00 \times 10^{0}$ & $1.50 \times 10^{5}$ \\
& {$\left[\mathrm{AcO}^{-}\right] /\left[\mathrm{Cu}^{2+}\right]=2$} & $4.30 \times 10^{13}$ & $\infty$ & $8.06 \times 10^{12}$ \\
& {$\left[\mathrm{AcO}^{-}\right] /\left[\mathrm{Cu}^{2+}\right]=4$} & $\infty$ & $\infty$ & $6.90 \times 10^{12}$ \\
Pheo $a$ & $\mathrm{CuTf}_{2}$ & $3.33 \times 10^{1}$ & $3.11 \times 10^{-1}$ & $4.28 \times 10^{14}$ \\
& {$\left[\mathrm{Cl}^{-}\right] /\left[\mathrm{Cu}^{2+}\right]=2$} & $2.75 \times 10^{9}$ & $3.24 \times 10^{7}$ & $8.64 \times 10^{14}$ \\
& {$\left[\mathrm{Cl}^{-}\right] /\left[\mathrm{Cu}^{2+}\right]=4$} & $6.22 \times 10^{9}$ & $6.28 \times 10^{7}$ & $5.41 \times 10^{14}$ \\
& {$\left[\mathrm{AcO}^{-}\right] /\left[\mathrm{Cu}^{2+}\right]=2$} & $8.56 \times 10^{16}$ & $\infty$ & $2.91 \times 10^{22}$ \\
& {$\left[\mathrm{AcO}^{-}\right] /\left[\mathrm{Cu}^{2+}\right]=4$} & $\infty$ & $\infty$ & $2.49 \times 10^{22}$
\end{tabular}

solutions. The difference in the redox potentials of the $\mathrm{Mg}$ complex and the free base does not account for the difference in the mechanism of electron transfer and its subsequent consequences.

\section{Conclusions}

Copper(II) ions are among the major metallic inhibitors of photosynthesis, both due to the abundance and reactivity of copper towards tetrapyrrolic compounds. The availability of different reaction pathways in chorophyll-Cu(II) systems in the presence of atmospheric oxygen, draws attention to specific components of the cellular environment, providing protection of the pigment molecules from oxidative degradation of the macrocycle. The presence of carboxylate groups in the coordination sphere of the metal ion is one way of significantly reducing its redox potential and thus the probability of chlorophyll degradation. In vitro, this effect can be explained first of all by the change in speciation, leading to an increase in the concentration of polynuclear forms of $\mathrm{Cu}$ (II) complexes. In such systems, the solvent plays an important role, since its solvation ability toward metal ions can significantly affect the speciation equilibria, inter alia, by stabilization or destabilization of the bridged forms.

Distinct differences between Chl $a$ and Pheo $a$, observed as a consequence of the occurrence of conditions that facilitate electron transfer, can be predicted by the different characteristics of the shapes of the oxidation bands in the electrochemical experiments. Reversible formation of the cation radical of Chl $a$ and degradation of the macrocyclic structure in Pheo $a$, are probably the result of some additional factors that require thorough investigation. A more in-depth insight into the mechanisms of these two different processes will be presented in a forthcoming report.

\section{Acknowledgements}

The work was supported by the National Science Center in Poland (Grant no. DEC-2012/05/B/ST5/00389). The Faculty of Chemistry of the Jagiellonian University is the beneficiary of the structural funds from the European Union, grant no. POIG. 02.01.00-12-023/08 "Atomic Scale Science for Innovative Economy (ATOMIN)". The authors thank Prof. Konrad Szaciłowski for valuable discussions and comments on electrochemistry. The work was in part supported by a research grant from the Foundation for Polish Science (Grant TEAM/ 2010-5/3 to L.F.).

\section{Notes and references}

1 S. J. Baum, B. F. Burnham and R. A. Plane, Proc. Natl. Acad. Sci. U. S. A., 1964, 52, 1439-1442.

2 T. Masuda, Photosynth. Res., 2008, 96, 121-143. 
3 J. D. Reid and C. N. Hunter, J. Biol. Chem., 2004, 279, 26893-26899.

4 C. J. Walker and R. D. Willows, Biochem. J., 1997, 327, 321333.

5 H. Küpper, F. Küpper and M. Spiller, Photosynth. Res., 1998, 58, 123-133.

6 H. Küpper, F. Küpper and M. Spiller, J. Exp. Bot., 1996, 47, 259-266.

7 H. Küpper, I. Setlik, M. Spiller, F. Küpper and O. Prasil, J. Phycol., 2002, 38, 429-441.

8 A. S. Brandis, Y. Salomon and A. Scherz, in Chlorophylls and Bacteriochlorophylls. Biochemistry, Biophysics, Functions and Applications, ed. B. Grimm, R. J. Porra, W. Rudiger and H. Scheer, Springer, Dordrecht, 2006, ch. 32, pp. 462483.

9 T. J. Dougherty, Photochem. Photobiol., 1993, 58, 895-900.

10 V. Rosenbach-Belkin, L. Chen, L. Fiedor, Y. Salomon and A. Scherz, in Photodynamic Tumor Therapy. 2nd and 3rd Generation Photosensitizers, ed. J. G. Moser, Harwood Academic Publishers, Amsterdam, 1998, pp. 117-125.

11 G. Hartwich, L. Fiedor, I. Simonin, E. Cmiel, W. Schafer, D. Noy, A. Scherz and H. Scheer, J. Am. Chem. Soc., 1998, 120, 3675-3683.

12 Ł. Orzel, R. van Eldik, L. Fiedor and G. Stochel, Eur. J. Inorg. Chem., 2009, 2393-2406.

13 W. Rüdiger, Photochem., 1997, 46, 1151-1167.

14 K. Iriyama, N. Ogura and A. Takamiya, J. Biochem., 1974, 76, 901-904.

15 T. Omata and N. Murata, Plant Cell Physiol., 1983, 24, 10931100.

16 a. d. o. U. o. K. a. TURBOMOLE V6.4 2012, -. Forschungszentrum Karlsruhe GmbH, s. a. f. TURBOMOLE GmbH and http://www.turbomole.com.

17 A. D. Becke, Phys. Rev. A, 1988, 38, 3098-3100.

18 P. A. M. Dirac, Proc. R. Soc. London, Ser. A, 1929, 123, 714-733.

19 J. P. Perdew, Phys. Rev. B: Condens. Matter, 1986, 33, 88228824.

20 J. C. Slater, Phys. Rev., 1951, 81, 385-390.

21 S. H. Vosko, L. Wilk and M. Nusair, Can. J. Phys., 1980, 58, 1200-1211.

22 K. Eichkorn, O. Treutler, H. Oehm, M. Haeser and R. Ahlrichs, Chem. Phys. Lett., 1995, 240, 283-290.

23 K. Eichkorn, F. Weigend, O. Treutler and R. Ahlrichs, Theor. Chem. Acc., 1997, 97, 119-124.

24 J. Heimdal, K. P. Jansen and A. Devarajan, J. Biol. Inorg. Chem., 2007, 12, 49-61.

25 Ł. Orzeł, A. Kania, D. Rutkowska-Żbik, A. Susz, G. Stochel and L. Fiedor, Inorg. Chem., 2010, 49, 7362-7371.

26 D. Rutkowska-Żbik and T. Korona, J. Chem. Theor. Comput., 2012, 8, 2972-2982.

27 D. Rutkowska-Żbik, M. Witko and L. Fiedor, J. Mol. Model, 2013, 19, 4661-4667.

28 A. Schaefer, C. Huber and R. Ahlrichs, J. Chem. Phys., 1994, 100, 5829-5835.
29 A. Klamt and G. Schüürmann, J. Chem. Soc., Perkin Trans. 2, 1993, 799-805.

30 M. Gouterman, J. Mol. Spectrosc., 1961, 6, 138-163.

31 M. Gouterman, G. H. Wagniere and L. C. Snyder, J. Mol. Spectrosc., 1963, 11, 108-127.

32 D. Sundholm, Chem. Phys. Lett., 1999, 302, 480-484.

33 D. Sundholm, Chem. Phys. Lett., 2000, 317, 545-552.

34 D. Sundholm, Chem. Phys. Lett., 2000, 317, 392-399.

35 Ł. Orzeł, J. Waś, A. Kania, D. Rutkowska-Żbik, L. Fiedor, M. Witko and G. Stochel, 2015, submitted.

36 D. Noy, L. Fiedor, G. Hartwich, H. Scheer and A. Scherz, J. Am. Chem. Soc., 1998, 120, 3684-3693.

37 T. Watanabe and K. Honda, J. Am. Chem. Soc., 1980, 102, 370-372.

38 T. Watanabe and M. Kobayashi, in Chlorophylls, ed. H. Scheer, CRC Press, Boca Raton, 1991, vol. 1.

39 D. C. Borg, J. Fajer, R. H. Felton and D. Dolphin, Proc. Natl. Acad. Sci. U. S. A., 1970, 67, 813.

40 M. S. Davis, A. Forman and J. Fajer, Proc. Natl. Acad. Sci. U. S. A., 1979, 76, 4170-4174.

41 D. A. Lightner, T. A. Wooldridge, S. L. Rodgers and R. D. Norris, Experientia, 1980, 36, 380-382.

42 K. S. Lee and L. M. Gartner, Pediatr. Res., 1976, 10, 782788.

43 Ł. Orzeł, L. Fiedor, A. Kania, M. Wolak, R. van Eldik and G. Stochel, Chem. - Eur. J., 2008, 14, 9419-9430.

44 M. Ulrich, S. Moser, T. Mueller and B. Kräutler, Chem. Eur. J., 2011, 17, 2330-2334.

45 B. Kräutler, B. Jaun, K. Bortlik, M. Schellenberg and P. Matile, Angew. Chem., Int. Ed. Engl., 1991, 30, 13151318.

46 B. Kräutler, B. Jaun, P. Matile, K. Bortlik and M. Schellenberg, Angew. Chem., Int. Ed. Engl., 1991, 30, 1315-1318.

47 J. Berghold, K. Breuker, M. Oberhuber, S. Hörtensteiner and B. Kräutler, Photosynth. Res., 2002, 74, 109-119.

48 D. Pocic, J.-M. Planeix, N. Kyritsakas, A. Jouaiti and M. W. Hosseini, CrystEngComm, 2005, 7, 624-628.

$49 \mathrm{~V}$. Gutmann, The donor-acceptor approach to molecular interactions, Plenum Press, New York-London, 1978.

50 F. L. Riddle Jr. and F. M. Fowkes, J. Am. Chem. Soc., 1990, 112, 3259-3264.

51 Handbook of Solvents, ed. G. Wypych, ChemTec PublishingWilliam Andrew Inc., Toronto - New York, 2001.

52 P. D'Angelo, E. Bottari, M. R. Festa, H.-F. Nolting and N. V. Pavel, J. Chem. Phys., 1997, 107, 2807-2812.

53 J. P. Chauvet, R. Viovy, R. Santus and E. J. Land, J. Phys. Chem., 1981, 85, 3449-3456.

54 J. Fajer, D. C. Borg, A. Forman, D. Dolphin and R. H. Felton, J. Am. Chem. Soc., 1973, 95, 2739-2741.

55 S. Sinnecker, W. Koch and W. Lubitz, J. Phys. Chem. B, 2002, 106, 5281-5288.

56 J.-H. Fuhrhop, K. M. Kadish and D. G. Davis, J. Am. Chem. Soc., 1973, 95, 5140-5147. 